\title{
Can videogames be used to develop the infant stage educational curriculum?
}

\author{
Verónica Marín Díaz ${ }^{1, *}$, Javier Martín-Párraga² \\ ${ }^{1}$ Department of Education, University of Cordoba, Spain \{vmarin@uco.es\} \\ 2Department of English and German Philology, University of Cordoba, Spain \{javier.martin@uco.es\} \\ Received on 21 September 2013; revised on 23 September 2013; accepted on 31 October 2013; published on 15 January 2014
}

DOI: $10.7821 /$ naer.3.1.20-25

\begin{abstract}
The utilization of videogames is not too common due to their consideration as an element that interferes with the educational and learning process. Thus, few teachers are ready to include videogames as didactic tools. Nevertheless, some educators who consider that they have a potential to become didactic tools are progressively adopting videogames as part of their teaching strategies. This paper presents the result of an academic experiment conducted with university students from the degree of Primary Education. The initial step in this experience consisted in determining whether videogames could be seen as another of the many tools employed to develop the infant stage educational curriculum. A survey was developed in order to achieve this goal. The interviewees answered this survey in two different stages, providing as a result that these future teachers would definitely be willing to incorporate videogames in their classrooms once they have been trained to do so.
\end{abstract}

KEYWORDS: VIDEOGAMES, UNIVERSITY STUDENTS, CURRICULUM, INFANT EDUCATION, TRAINING

\section{INTRODUCTION}

The development of information and communication technologies (ICTs) has allowed our modern society to advance at a very fast pace. This movement aims at building a more technological world that will supposedly simplify people's lives.

These new technologies consequently imply a change of the utmost significance in the way people behave in their daily activities. From this point of view, all the surviving traditions which still remain significant in social movements are being incorporated (Marín, 2012a). These traditions have become very important because, in some ways, they are the ones conditioning the development of ICTs, together with many other social aspects.

This is a very ambitious approach, since it includes many perspectives, including social, political, ethical and educational ones. Nevertheless, it also raises some new important issues that can be said to belong within the main category of e-exclusion an increasingly important problem. Why is this aspect taken into account? It must be remembered that the ICT utilization depends on many factors, among which stand out economic, geographic,

\footnotetext{
${ }^{*}$ To whom correspondence should be addressed:

Departamento de Educación

Facultad de Ciencias de la Educación

Avda. San Alberto Magno, s/n

14004 Córdoba

Spain
}

social, political and educational ones. Participation in actions and activities involving ICTs in general and 2.0 tools is becoming more frequent (Cheung \& Vougue, 2013). Thus, new and undesired scenarios of technological inequality will most probably arise in the near future.

That is the reason why the progressive introduction of ICTs in classrooms not only implies a change in teaching methodologies combined with a new understanding of the teaching-learning process, but also a systematic and measured destruction of the so-called digital divide.

Of all the new fast-growing new technologies, 2.0 tools and videogames appear as the most popular ones among the classroom population across the different educational levels. The reaction to 2.0 tools and videogames ranges from a love-hate relationship to cases in which they are much present in daily teaching. Therefore, those teachers who are trying to develop their students' curriculum and make their contents more attractive for them must consider the possibility of using both 2.0 tools and videogames, since they are key elements within the long-awaited and much-needed academic innovation.

\section{VIDEOGAMES AND EDUCATION}

As stated previously, ICTs are becoming a reality both for students and for the teaching staff. This rising trend has been characterized by the strong growth of new technologies use in private homes, educational and working centers and, in general, in every area where human beings have advanced in recent years.

The development of the Internet has led to the implementation of new teaching methodologies where teachers as well as students assume the new roles that the knowledge society has created for them. This is a new perspective in which aspects such as collaboration, collaborative work, innovation, and the ability to look for new information in an analytical manner become essential. As can be seen, all these features form part of curricular development at the various educational levels.

Technological tools, or 2.0 tools as they are known nowadays, have developed simultaneously with the Internet. This new Web 2.0 environment is defined by: the bidirectional exchange of information; the collective construction of knowledge; its open participation system, and the free availability of most tools (O'Reilly, 2005). In other words, these are the main features of the Web 2.0 which human beings love and/or hate and with which they have to live and work day in day out.

Technological growth has also resulted in a desire to instruct our students in the so-called "digital literacy." Sharing the 
opinion expressed by Bustos (2009) -though with some nuances- leads us to state digital literacy clearly involves much more than the mere ability to use a computer. Our conception of digital literacy focuses on "the ability to understand and use information in a variety of formats from a wide range of sources" and also to be able to present that information in coherent, pleasant and varied ways".

Within this frame, videogames -both online and offline onesemerge as one of the technologies that have evolved to a greater extent. Generally speaking, videogames have been catalogued as mature or educational and mainstream.

It is our conviction that videogames offer educators an ideal tool which gives his students the possibility to create, model and modify their closer environment using a tool which they find attractive and which additionally forms part of their social relationship, both with other students and with the society as a whole.

A recent study presented by the Spa nosh Association of Editors and Distributors of Entertainment Software (aDeSe, www.adese.es) pointed out that in 2012, 58\% of Spanish citizens (compared to $67 \%$ of Europeans) considered it positive to utilize entertainment software and videogames as educational tools.

The results of the Gametrack: The Videogames in Europe Consumer Study (developed by the Interactive Software Federation of Europe (ISFE) are similar insofar as they prove that $47 \%$ and $25 \%$ of Europeans believe that video games foster young people's creative and social skills. This tendency to include videogame consoles in European citizens' daily life is reflected on the growing sales of both consoles and accessories.

In the case of Spain, the videogame industry reached 822 million euros in consumer sales in 2012 (aDeSe, 2012). These outstanding economic results in mind lead us to think that videogames are obviously much more than a mere entertainment option that replaces traditional games.

In terms of categories, traditional games (platforms, strategy, sports, racing, arcade...) have traditionally been the most popular ones -a trend which is repeated in the last two years (74.7\% in 2012 and $79.8 \%$ in 2011).

Taking into account that some curricular contents are very difficult to be taught to students, it would be very useful for us to bear in mind how frequently they use videogames in their daily life. In this respect, the aforementioned 2012 aDeSe report states that $30 \%$ of Spanish educators use videogames as curricular tools. More specifically, according to $78 \%$ of Spanish Infant Education teachers, videogames "offer a great pedagogic potential and introducing them in the classroom can be considered as a refreshing new teaching method (aDeSe, 2012, p. 32).

Considering the above, videogames should definitely be integrated into the catalogue of digital tools that teachers must use in their classrooms. What is more, both educators and students must assign videogames an educational value because every videogame can contribute to a greater or lesser extent to education and teaching. "The utilization of videogames and digital games for educational purposes must begin with the study of the relationships established between the universe that these games create and the gamers themselves. The latter must be able to interpret these messages, but this is a handicap because sometimes this universe is not accurately interpreted -such an inability for interpretation must derive from gamers' ignorance of the iconic code or from a lack of knowledge of the message itself" (Marín, 2012b, p. 194).
In any case, what educational value can be assigned to videogames? To start with, videogames have the capacity to foster curiosity and a desire to learn, even if most of that learning takes place at an unconscious level. Thus, videogames contribute to develop certain skills and the curriculum gets reinforced in a crosswise manner while students' self-awareness and esteem simultaneously grow (Marín \& García, 2005). According to aDeSe (2012), using video videogames in the classroom is beneficial in the following ways:

$$
\begin{aligned}
& \text { — Students' motivation for content study is increased. } \\
& \text { — Students pay more attention and get easily focused. } \\
& \text { — Videogames reinforce curricular content learning. } \\
& \text { — Videogames attract students' attention and retentiveness. } \\
& \text { — When using videogames, learning is fun, so students don't } \\
& \text { get demotivated when faced with complex topics. } \\
& \text { — Mental ability is increased. } \\
& \text { — The classroom and its dynamics become more attractive. } \\
& \text { — Videogames are part of our students' reality. } \\
& \text { — Videogames serve as an entry point to the technological } \\
& \text { world. }
\end{aligned}
$$

Marín (2012a, 24) points out that "videogames also develop reflexive and critical thinking, attention and memory skills, collaborative work capacities, as well as a desire to improve and interact with other students. Videogames also enhance students' visual and spatial skills, as well as their hand-eye coordination, and largely contribute to develop students' capacity, not only to prevent and solve conflicts but also to discover and learn new vocabulary and numerical conceptions. At the same time, video games increase motivation levels and help in the formation of socially accepted standards of behavior that replace impulsiveness and self-destructive tendencies". It is also worth mentioning that videogames can be used to reduce students' anxiety and are also useful to treat some types of mental or physical impairment.

Our bottom line is that including video games as a technological tool in classrooms at any educational level brings highly positive results, because:

(1) They improve students' appetite for learning.

(2) They promote the development of personal, social, communicative skills...

(3) They allow students to develop their curriculum transversally.

(4) They bolster self-esteem and the self-image that students project towards other people (Marín, 2012a).

The preceding criteria make it clear for us that an urgent need exists to overcome the negative perception of videogames as a mere waste of time that steals time from study, social interaction, etc. Another misconception that must be cleared is the one assuming that videogames promote violent or anti-social behaviors and attitudes.

As proved by the 2011-2012 aDeSe study proved, a third of educators $(36.4 \%)$ used videogames as didactic tools. It is important to highlight that younger teachers (up to 39 years of age) were more willing to utilize video videogames. Therefore, it is safe to assume that a relevant percentage of educators are changing their previous negative view on videogames. 
On the other hand, the Spanish Education Act (Ley Orgánica de Educación) from 2006 as well as the new one that is now been debated upon in Parliament (known as LOMCE, 2013) give a privileged place to information and communication technologies. In the case of the former, these new technologies are included in the teaching of basic skills both in Primary and Secondary Education -they are introduced in a very light manner in the case of Infants and Pre-school Education, though. As for the new Law-LOMCE- it treats these new technologies in the same way as the previous Law in the areas of Infant, Preschool and Primary Education, and assigns even more importance to ICTs in Secondary Education (High Schools).

Even though the Law allocates less importance to the use of ICTs in early education, it would be a mistake to conclude that their educational value is less important in that area. On the contrary, it seems obvious to us that using ICT in early education helps to achieve a great improvement in terms of curricular development -these benefits become particularly visible in subjects that prove more demanding for younger students. Therefore, in our opinion, the utilization of videogames in the classroom constitutes both a challenge and an exciting adventure for students and teachers alike.

Using video games that are labeled as educational offers the following advantages: "They allow us to exercise fantasy beyond spatial, temporal or gravity limitations. In contrast with conventional and static classrooms, the graphics allow us to enter "other worlds." Videogames promote instantaneous repetition and new attempts in a safe environment. They help students to master different skills because, even if actions are difficult, children can repeat them until they achieve their goal, acquiring feeling of control. Unlike the classroom social dynamics, students can interact in a non-hierarchical manner when using videogames. The goals are easily perceived. Generally, a child is not aware of what he is studying in math, or social sciences. On the other hand, when he is playing a videogame the task becomes clear and specific: to open a door, to rescue someone, to find a treasure, etc. As a result, motivation in these cases is very high. Videogames foster attentiveness and self-control while at the same time they reinforce the concept that individual success can be achieved by changing the environment (instead of changing oneself)" (Padilla, 2007).

Regardless of all the positive aspects that have been considered so far, before introducing a videogame as a curricular tool, it is necessary to ask ourselves whether it stimulates our students' ability to improve, the extent to which it is understood by students as a challenge and at the same time if it is beneficial for their interpersonal relationships and helps them not only to learn in a meaningful way but also to make decisions and solve problems. In general, there is a need to judge whether the videogame is useful from a didactic point of view and fosters autonomous learning (Marín, Ramírez \& Cabero, 2010; Torrico, 2008).

\section{USING VIDEOGAMES TO DEVELOP THE DEGREE OF INFANT EDUCATION}

The following experience was included in the curriculum of the subject Media Education and Educational Dimension of ICTs. It is a subject taught in the Degree of Primary Education at the University of Córdoba. In this case, a video game called Lemmings, and the students had to assess whether this videogame could be used in the classroom when teaching children from the third year of Primary Education.
Our choice of this videogame was based on the belief that it would help our students to acquire the technological skills which are listed below- included in the subject syllabus:

- CU2 To know and perfect ICTs at user level.

- CE7 To know the educational implications of information and communication technologies in general -and of TV in particular- within the context of Early Education.

- CM3.4 To analyze and incorporate into their teaching activities those social questions that might affect primary education; the social and educational impact of audiovisual and screen languages; changes in gender-related and intergenerational relations; multiculturalism and interculturality; exclusion and social inclusion and sustainable development.

- CM6.3 To carry out fieldwork using information and communication technologies.

- CM7.2 To be aware of international projects and innovative experiences in the field of Primary Education.

- CM8.9 To foster experiences to introduce information and communication technologies.

- CM10.5 To analyze audiovisual languages and their educational implications.

- CM11.3 To master the techniques and strategies required to control and monitor the educational process.

- CM11.4 To relate theory to practice in the classroom" (Subject Syllabus, 2012).

It becomes evident that the subject introduces students into ICTs in a comprehensive manner, without leaving any areas out of the study.

The educational experience was developed as follows:

$1^{\text {st }}$ Information about the videogame: First of all, a lesson was imparted to students for the purpose of explaining the evolution of videogames along with their didactic possibilities. Some real examples from previous experiences were given to them before explaining the videogame that they were going to use on this occasion, i.e. Lemmings. Thus, students were told that the game first appeared in 1991 for PCs and was subsequently adapted for videogame consoles. The goal of the game is pretty straightforward and consists in saving the maximum number of Lemmings. In order to achieve this goal, gamers are provided with 8 different skills: they can dig in different directions to create tunnels; they can parachute; they can build 12-step stairs; they can block and, finally, they can use bomb-lemmings which are turned into bombs to blow up obstacles (Marín, Ramírez \& Cabero, 2010).

$2^{\text {nd }}$ Preliminary survey: After the introductory session, a survey questionnaire was administered to students that they would have to answer again after finishing the experiment.

$3^{\text {rd }}$ Experimentation with the videogame: During this step, students tried the video game on their own, in the computer room or using their own laptops.

$4^{\text {th }}$ Final survey: After testing the videogame, students had to answer the same survey, in order to see whether or not their attitudes had changed.

$5^{\text {th }}$ Development of didactic proposals: In the last step of this experience, students were ask to prepare their own teaching activities -considering curricular area, contents and goalsthat were meant to be incorporated in the teaching of the third 
year of Primary Education with students that range from 4 to 5 years of age.

All five steps were developed in the classroom, except for the fifth one that could be made in a semi-virtual modality.

\section{EMPIRICAL STUDY}

The general goal sought with this educational action was to help students to check how videogames could become a central methodological tool in the early education curriculum.

The research was quantitative and quasi-experimental. The initial study population included all the students enrolled in the Media Education and Educational Dimension of the ICT course, which is taught at the Degree of Primary Education $(\mathrm{N}=71)$. Finally, the sample studied was comprised by 65 students, $97.2 \%$ of whom were women and $2.8 \%$ men. A bias in the measurement could be observed but as pointed out by Gialamas, Nikiolopoulu \& Koutromanos (2013) and also by Cheng \& Chang (2006), Early and Primary Education degrees are studied mostly by women worldwide. Hence our decision not to accept such bias, since the number of men and women enrolled in these subjects cannot be controlled by researchers.

The questionnaire included 10 items in Likert-like scale with 5 options, where 1 would mean total disagreement and 5, total agreement. The expert judgment technique was used to validate the research. Therefore, the judges were selected in accordance with the following criteria: they had to be teachers of subjects that were directly related to ICT; they had to be teaching in the field of educational technologies; and the teaching had to have occurred within the previous seven years. Three experts were finally selected (two men and a woman from the Universities of Córdoba and Jaén). After evaluating the questionnaire, only one item was deleted (to judge the degree of knowledge of quantities), since it was implicitly included in the other questions. The final questionnaire therefore included the following 9 items:

- Learning to work cooperatively and collaboratively in the context of teamwork

- To distinguish the parts of the body

- To learn the synchrony between the upper and lower parts of the body

- To distinguish primary and secondary colors

- To develop heuristic thinking (trial and error)

- To self-regulate the learning process (ongoing assessment)

- To develop inductive thinking

- To develop visual memory and retentiveness

- To know the concepts of success and failure, up-down, inside-outside, before-after, and front-rear.

This instrument was validated through a Cronbach's Alpha test, scoring 0.97. According to Mateo (2004), this average must be regarded as very high. The item-by-item results were:
Table 1. Cronbach's Alpha, item by item.

\begin{tabular}{lc}
\hline Ítem & Alpha \\
\hline Learning to work in a cooperative and collaborative way in the & .976 \\
context of teamwork. & .893 \\
To distinguish the body parts & .994 \\
To learn the synchrony between upper and lower body parts. & .923 \\
To distinguish primary and secondary colors. & .955 \\
To develop heuristic thinking (trial and error). & .899 \\
Self-regulation of the learning process (continuous evaluation). & .932 \\
To develop inductive thinking.. & .955 \\
To develop visual memory and retentiveness. & .677 \\
To know the concepts of success and failure, up-down, inside- & \\
outside, before-after, front-rear. &
\end{tabular}

As can be seen, the item-by-item analysis did not reveal a decrease in the reliability of our instrument.

\section{RESULTS}

The questionnaire results - expressed for each different itemare shown next:

\subsection{Learning to work cooperatively and collaboratively in the context of teamwork}

Before using the videogame, $89 \%$ of students claimed to completely disagree with item $1,6 \%$ of them said that they were indifferent, and the remaining $5 \%$ agreed with it. After experiencing the game, the results of the second questionnaire (post-test) show that $76 \%$ of students fully agree with the idea that this video game helps to develop the curriculum in a crosswise manner, $17 \%$ of students disagreed, $4 \%$ claimed to be indifferent, and only $3 \%$ totally disagreed.

\subsection{To distinguish the parts of the body parts}

In the pre-test, $77 \%$ of participants totally agreed, $14 \%$ of them were indifferent, $6 \%$ disagreed, and $3 \%$ totally disagreed.

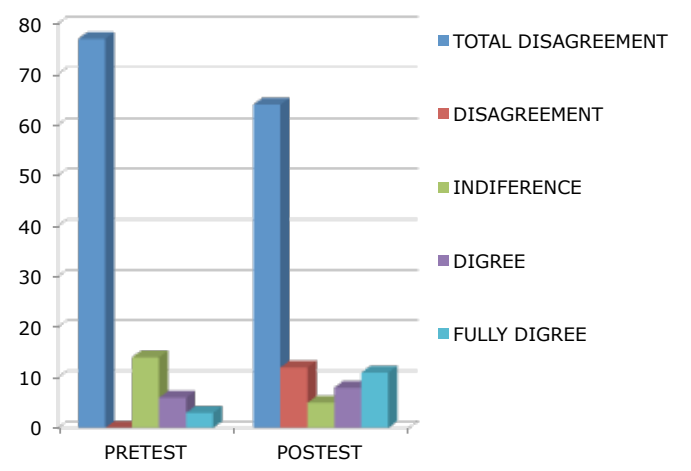

Figure 1. Item 2: pre-test and post-test

In the case of the post-test, results range from $64 \%$ to $12 \%$ that showed total disagreement and disagreement. $5 \%$ of them expressed indifference and $8 \%$ and $11 \%$ respectively claimed to agree or fully agree.

\subsection{To learn the synchrony between upper and lower parts of the body}

This time the first questionnaire showed $92 \%$ and $4 \%$ respectively claiming to disagree or fully disagree. Only $4 \%$ chose the third option, i.e. indifference. 


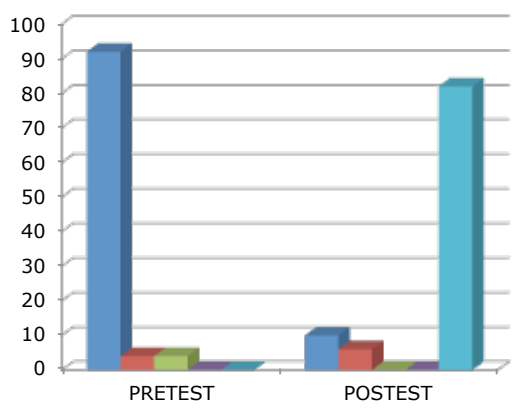

-TOTAL DISAGREEMENT

- DISAGREEMENT

INDIFERENCE

- DIGREE

a FULLY DIGREE

Figure 2. Item 32: pre-test and post-test

The results in the post-test were as follows: $82 \%$ of students said that they fully agreed with the statement that this game contributed to distinguish and assimilate the synchrony between the upper and lower parts of the body. $10 \%$ of students disagreed, and $6 \%$ fully disagreed.

\subsection{To distinguish primary and secondary colors}

In this case, the results in both the pre-test and the post-test are included in two categories: $78 \%$ so students disagreed, while $22 \%$ of them agreed in the pre-test and $84 \%$ and $16 \%$ showed indifference.

\subsection{To develop heuristic thinking (trial and error)}

$100 \%$ of students chose the fully agree with this option in the post-test, but initially (in the pre-test) $94 \%$ of them claimed to be indifferent, and $6 \%$ disagreed.

\subsection{To self-regulate the learning process (continuous assessment)}

In the pre-test, $64 \%$ and $14 \%$ respectively fully disagreed and disagreed; $17 \%$ were indifferent, and only $5 \%$ agreed. The results of the post-test are especially meaningful, since they show continuity: $87 \%$ of students claimed to fully disagree, $4 \%$ disagreed; $3 \%$ chose the indifferent option, and $2 \%$ and $4 \%$ respectively said that they agreed and fully agreed.

\subsection{To develop inductive thinking}

Similarly to what happened for item 4 , students are distributed in two categories: fully disagree $(84 \%$ and $56 \%$ in pre-test and the post-test) and indifference ( $16 \%$ and $44 \%)$.

\subsection{To develop visual memory and retentiveness}

In item 8 , students grouped themselves together around 3 answers. In this case, the results of the pre-test significantly differ from those obtained in the posttest. In the first questionnaire, $98 \%$ of students disagreed and only $2 \%$ were indifferent. But, after the experience, students did choose the positive options (fully agree and agree, $56 \%$ and $43 \%$ ) and only $1 \%$ remained indifferent.

\subsection{To know the concepts of success and failure, up- down, inside-outside, before-after, and front- rear}

Exactly the same as in item 5,100\% of students agreed that this videogame helps students to know the concepts of success and failure, up-down, inside-outside, before-after, and front-rear, both in the pre-test and in the post-test.

Based on the results of our initial exploration, a proposal is made to develop a lesson plan aimed at the students that our trainee teachers would hypothetically have in their classroom, that is to say, those at the third year of early education. Most of the students developed lesson plans related to the Math and Value Formation areas. Neither of these areas is contained per se in the 2006 Spanish Education Act ("Ley Orgánica de Educación") or in the Decree 428/2088 that establishes the minimum teaching requirements for Andalusia. Nevertheless, it can be understood that such areas are included within the three macro areas contained in the Decree (Self-knowledge and personal autonomy; Knowledge of the environment and languages; Communication and representation).

As an example, it seems interesting for us to show an action related to Math. Why is this videogame considered as a good teaching tool for this specific curricular area? Because it gives the children the opportunity to improve their calculus and logic skills, since they handle objects and collections. Therefore, they can identify their qualities and main features and also establish groups, classifications, orders and quantification.

Our proposal refers to the area of Math and has as its general goals: (a) To know one's own and others' bodies, to learn the possibilities offered by the body; and to learn to respect differences) and (b) To take the first steps towards the acquisition of the logic and mathematics as well as the reading and writing skills, and those related to movement, expression and rhythm. The specific goals to be achieved would be the following ones:

- To develop mathematical skills, such as ordering, quantifying and classifying

— To develop logic-related skills by solving problems

- To use the computer in a playful manner

- To carry out experiments and analyze their results

- To know basic concepts related to quantity and space

These aspects would be developed through the use of videogames, in order to acquire the following contents:

Conceptual: Cardinal numbers and classification

Procedural: Identification of game functions and uses; Classification and organization of Lemmings according to their specific circumstances; Utilization of counting; first contacts with numbering series, additions and subtractions.

Attitudinal: To show interest and ability to take care of the objects that they have utilized; and interest towards the classification of elements.

\section{CONCLUSIONS}

As Drent \& Meelisse pointed out in 2008, it is sometimes assumed that by simply using the ICT in the classroom teachers are developing technological curricular innovation and, consequently, achieving a better and more direct and effective learning. It is not our intention here to deny an idea that is also supported by us but, at the same time, it is our conviction that Higher education should train future educators in the use and consumption of ICTs within the educational context.

Any technology which has not been developed with an educational aim from the very beginning is not educational per se, so there is a need to study its possibilities in order to consider it as a didactic tool. This is exactly the case with videogames. And in this case, the situation becomes even more complex, since videogames tend to be considered as negative elements. Starting from this negative position, our research has proved that videogames can be useful in the educational processes (see also 
Marín, 2012a). In fact, the results of our instrument are in keeping with those obtained by Lacasa, Martínez-Borda, Méndez, Cortés \& Checa's 2010 in a similar experiment.

On the other hand, Qasim Medhi, director of the Games Simulation and Artificial Intelligence Centre, considers that the educational value which has been added to videogames in recent times justifies the expression G-LEARNING. Initially, the results obtained in our pre-test would make us question this statement but it has also been proved that an educational action regarding videogames can modify previous negative conceptions. Thus, their educational value can easily be assumed.

Ruíz, Montero, Díaz \& López explained in 2008 that contemporary classrooms have a heterogeneous nature and are populated by groups who become more autonomous when working with ICTs in general and videogames in particular. As a result, didactic methodologies are currently being readjusted. This encourages us to do further work in the direction of experiences like the one described in this paper.

Finally, it deserves to be mentioned that videogames are extremely attractive due to their great visual and auditory appeal, to the fact that they allow users to save games (that is to say, to program and store), to the complexities of their topics, and also because they offer the possibility of playing with some other players who might be thousands of miles away. All these are advantages offered by videogames that need to be taken into account both by the society as a whole and by educational institutions and authorities, since they can enable students to check their own evolution and growth which, in turn, boosts their desire to participate and learn.

\section{REFERENCES}

aDeSe (2012). Anuario de la industria del videojuego 2012. Retrieved from http://www.adese.es/anuario2012/ANUARIO_ADESE_2012.pdf

Bustos, A. (2009, March). Alfabetización digital y currículum escolar. Paper presented at the I Jornadas Educación y TIC, Torreón, México. Retrieved from http://www.slideshare.net/alfonso.bustos/bustosjornadas-tic-2009-final

Cheng, J., \& Chang, C. (2006). Using computers in early childhood classrooms: teachers' attiudes, skills and practices. Journal of Early Childhood Research, 4(2), 269-288.

Cheung, R., \& Vogue, Dang (2013). Predicting user acceptance of collaborative technologies: an extension of the technology acceptance model for e-learning. Computers \& Education, 63, 160175. doi: 10.1016/j.compedu.2012.12.003

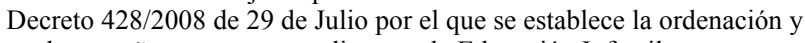
las enseñanzas correspondientes a la Educación Infantil en Andalucía. Retrieved from http://www.juntadeandalucia.es/boja/boletines/2008/164/d/updf/d2.p df

Drent, M., \& Meelissen, M. (2008). Which factors obstruct or stimulate teacher educators to use ICT innovatively? Computers \& Education, 51, 187-199. doi: 10.1016/j.compedu.2007.05.001.

Gialamas, V., Nikolopouiou, K., \& Kutromanos, G. (2013). Student teachers' perceptions about the impact of Internet usage on their learning and jobs. Computers \& Education, 62, 1-7. doi: 10.1016/j.compedu.2012.10.012

Lacasa, P., Martínez-Borda, R., Méndez, L., Cortés S., \& Checa M. (2008). Aprendiendo con los videojuegos comerciales. Un puente entre ocio y educación. Retrieved from http://www.aprendeyjuegaconea.com/files/informe_UAH_2007.pdf.

Ley Orgánica 2/2006, de 3 de mayo, de Educación (Boletín Oficial del Estado número 106, de 4 de mayo de 2006).

Ley Orgánica 8/2013, de 9 de diciembre, para la Mejora de la Calidad Educativa (Boletín Oficial del Estado número 295, de 10 de diciembre de 2013).
Marín, V. (2012a). El ayer y el hoy de los videojuegos. In V. Marín (Coord.), Los videojuegos y juegos digitales como materiales educativos (pp. 19-34). Madrid: Síntesis.

Marín, V. (2012b). Investigando sobre el potencial psicosocioeducativo de los videojuegos y juegos digitales. In V. Marín (coord.), Los videojuegos y juegos digitales como materiales educativos (pp.193218). Madrid: Síntesis.

Marín, V., \& García, M. D. (2005). Los videojuegos y su capacidad didáctico-formativa. Pixel-Bit. Revista de Medios y Educación, 26, 113-119.

Marín, V., Ramírez, A., \& Cabero, J. (2010). Los videojuegos en el aula de primaria, propuesta de trabajo basada en competencias básicas. Comunicación y Pedagogía, 244, 13-18.

Mateo, J. (2004). La investigación ex post-facto. In R. Bisquerra (coord.). Metodología de la investigación educativa (pp.195-230). Madrid: La Muralla.

O'Reilly, T. (2005, September 30). What Is Web 2.0. Design Patterns and Business Models for the Next Generation of Software [Web log message]. Retrieved from http://oreilly.com/web2/archive/what-isweb-20.html

Padilla, N. (2007). El uso educativo de los medios. Retrieved from: http://www.juntadeandalucia.es/educacion/webportal/descargas/famil ias-lectoras/flash/coleccion/resources/cariboost_files/cuaderno09.pdf.

Ruíz, M., Montero, M. E., Díaz, B., \& López, C. M. (2008). Videojuegos para tender puentes. Diálogo y aprendizaje puestos en juego. Comunicación y Pedagogía, 217, 39-45

Torrico, M. A. (2008). La Nintendo DS en el aula ordinaria. Propuesta metodológica. Comunicación y Pedagogía, 231/232, 27-30 